\title{
Rompiendo con los esquemas de la transparencia
}

CP 2015 , Vol.4-Nº (Monográfico II), pp. 60-63. ISSN 2014-6752. Girona (Catalunya). MARTíNEZ FERNÁNDEZ, Ángela Paloma: La sociedad de la transparencia. Recibido: 08/11/2015 - Aceptado: 11/11/2015

\section{La sociedad de la transparencia}

Byung-Chul Han

Barcelona.

Herder, 2013.

95 páginas

ISBN 978-84-254-3252-1

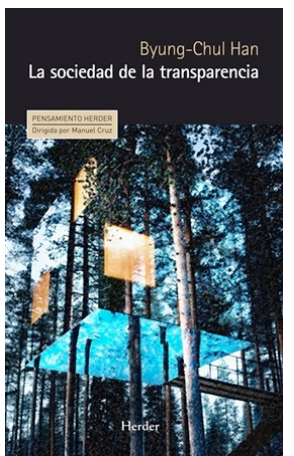

\section{Ángela Paloma MARTín FERNÁNDEZ}

Directora de Ideograma LATAM y Consultora política en Ideograma. angelap@ideograma.es

\section{Reseña}

Esta obra se puede considerar un ensayo en toda su estructura. Una amplia reflexión fruto del análisis del concepto de "transparencia" y el impacto que produce directamente en las sociedades del hoy, pero también del ayer y del mañana. Está dividida en nueve capítulos: i) La sociedad positiva; ii) La sociedad de la exposición; iii) La sociedad de la evidencia; iv) La sociedad del porno; v) La sociedad de la aceleración; vi) La sociedad íntima; vii) La sociedad de la información; viii) La sociedad de la revelación; y ix) La sociedad del control. Pero aunque la división sea por capítulos, lo cierto es que muchos de ellos están relacionados. Y el contenido de uno podría ser perfectamente motivo de desarrollo de otro.

La trayectoria del autor, Byung-Chul Han (filósofo de la Universidad de Fribugo y Literatura alemana y Teología en la Universidad de Múnich, y actual profesor en la Universidad de las Artes de Berlín), hace más atractivo el análisis del concepto de transparencia. ¿Por qué? Por un lado, porque su formación y su reflexión se nos hace más atractiva a aquellos que nos dedicamos a la comunicación, y cuyo objetivo de reflexión es protagonista de nuestra profesión. Y también, porque en la actualidad, y sobre todo desde el pedestal político, diferentes movimientos y diferentes políticas están impulsando el concepto de transparencia como un deber frente a la sociedad, como algo que se le debe a los ciudadanos, más aún en este momento de cansancio colectivo, de frustración coral, de desgana en masa, de crítica tenaz. La comunicación puede mejorar la calidad democrática, pero... iy la transparencia? Byung-Chul Han rompe con los esquemas de transparencia que se vienen defendiendo en los últimos años como mecanismo para ganar confianza y credibilidad. Rompe con el esquema de la transparencia como principio. Y no sólo rompe con los esquemas, sino que también le pone límites e introduce un nuevo concepto en sus justificaciones: el de la pornografía.

El concepto de transparencia que se viene defendiendo hasta el momento, sufre una crisis con la reflexión que hace Han en este 
libro. Un parón, una llamada de atención, un despertar frente a los límites. Unos límites con los que se puede o no estar de acuerdo. Pero unos límites, al fin y al cabo, sustentados en argumentos bibliográficos y en teorías de diferentes autores como Humboldt, Baudrillard, Simmel, Nietzsche, Sennet o Schmit. A pesar de la brevedad del libro, la riqueza de bibliografía destaca.

Pasando al contenido, cabe señalar que, desde el primer momento, el autor menciona el concepto de pornografía en la sociedad de la transparencia y lo define: "Pornografía es el contacto inmediato entre la imagen y el ojo". Para los que esperaban otro concepto, Han defrauda. Para los profesionales de la comunicación, este concepto es una revelación de la evidencia que hay que tener siempre presente. $\mathrm{Y}$ continúa con la definición de "la sociedad de la transparencia". Para él, "la sociedad de la transparencia es un infierno de lo igual”. Han defiende que "sólo la máquina es transparente. La espontaneidad, lo que tiene la índole de un acontecer y la libertad, rasgos que constituyen la vida en general no admiten ninguna transparencia". Y afirma que es "ingenua "la ideología del la PostPrivacy" puesto que "exige en nombre de la transparencia un total abandono de la esfera privada, con el propósito de conducir a una comunicación transparente".

\section{Política}

En ocasiones, se ha unido el concepto de transparencia a la idea de aportar más información. Pero, como señala Gigerenzer, está demostrado que más información no conduce de manera necesaria a mejores decisiones. En relación a la política, señala: "La política es una acción estratégica. Y, por esta razón, es propia de ella una esfera secreta. Una transparencia total la paraliza. El "postulado de carácter público", dice Carl Schmitt, tiene su adversario específico en la idea de que toda política lleva consigo cosas arcanas, secretos de técnica política, que de hecho son tan necesarios para el absolutismo como los secretos comerciales y empresariales para una vida económica que se basa en la propiedad privada y en la ocurrencia”. Según Han, si lo antes mencionado fuese cierto, "el final de los secretos sería el final de la política", y equivaldría al desarrollo de la pospolítica, "que equivale a la despolitización". De esta reflexión, se puede obtener la conclusión de que la transparencia máxima en política estaría formada por opiniones finalmente, no por ideologías ni proyectos políticos.

A partir del fenómeno tecnológico y la comunicación digital a través de herramientas como las redes sociales, se puede haber banalizado el concepto de transparencia. La sociedad es vigilante y crítica con sus representantes, demandan que sean transparentes para así evaluar si es verdad o no, puesto que como electores y ciudadanos tienen el derecho de saber y conocer la verdad. No obstante, el concepto de transparencia en el mundo del "me gusta" o del "favorito" se puede haber prostituido. Si bien igual no se está de acuerdo con algunas de las ideas en los límites de la transparencia que propone Hang, lo cierto es que hay una afirmación que cabe subrayar: "transparencia y verdad no son idénticas. (...) Más información o más acumulación de información por sí sola no es ninguna verdad. Le falta la dirección, a saber, el sentido. (...) La hiperinformación y la hipercomunicación dan testimonio de la falta de verdad, e incluso de la falta de ser. Más información, más comunicación no elimina la fundamental imprecisión del todo. Más bien la agrava”.

\section{La exposición que afecta a las mujeres}

En comunicación y en política, la exposición pública es un elemento más del día a día. No obstante, Han presume de haber llegado a la reflexión de que la alta exposición acaba siendo pornográfica. Si pensamos en la comunicación política y en las estrategias, 
vemos como la exposición cobra un mayor protagonismo en el caso de las mujeres. Ocurre también en el caso de los hombres, pero son ellas las que obtienen un mayor protagonismo mediático y mayor opinión pública no tanto por cómo piensan, ni por lo que dicen, ni tampoco por lo que proponen. La exposición en política en el caso de las mujeres es un examen continuo que no siempre juega a su favor. Exponer más para demostrar capacidades y con ello ganar confianza no es suficiente. Para Hang sería pornografía.

Hang apunta que la exposición en sí es pornográfica: "la exhibición directa de la desnudez no es erótica. El lugar erótico de un cuerpo está precisamente allí "donde" se abre el vestido, es la piel que brilla "entre dos piezas". Y "no es sublime, sino obsceno el cuerpo que se hace carne". Aunque parezca en sí erótico, hay que traducir la reflexión de Byung-Chul Han en el ámbito de la comunicación pública. Si pensamos por un instante en las fotografías que encontramos a diario en las redes sociales, vemos un exceso de exposición que, en muchas ocasiones, no concuerda con la vida real de uno mismo. ¿De qué sirve entonces la exposición con el fin último de ser transparente cuando lo que conseguimos al final es mera apariencia que no genera interés en los demás? A nivel profesional, hay que pensar en estrategias de comunicación en una sociedad infoxicada, sobre expuesta.

$\mathrm{Si}$ "descubrir y descifrar se realizan como un desvelamiento agradable”, ¿por qué no pensamos en estrategias de comunicación enfocadas a la confianza, sin abandonarnos y proyectadas hacia el que nos descubran poco a poco para generar mayor interés? Los límites de Hang en la sociedad transparente invitan a pensar en nuevos acepciones y estrategias para la implementación de la transparencia en el ámbito político.

\section{La comunicación estratégica y la imagen}

La pornografía de Hang deja al descubierto formas de trabajar el ámbito de la comunicación que no han pasado por la creatividad, sino por la exposición en su máxima expresión. Esta obra invita a pensar en cómo la erótica del poder se ha convertido en la protagonista misma de la política: y se empieza a valorar más a los representantes políticos por cómo son físicamente - $\mathrm{o}$ cómo se exponen- y por las historias de cama que abren portadas en medios y revistas. ¿En qué momento pasaron a un segundo plano las necesidades sociales? Es erróneo cuando la crítica y la actuación política entra en el plano de lo personal y se abandona el hecho mismo de la representatividad social. El valor de la honestidad margina finalmente a la transparencia. Cuando hay confianza, ya no se necesita nada más.

Las imágenes en política, también son política. La creatividad en las mismas, por naturales, las hacen más auténticas, más políticas, más influyentes y, por ello, más movilizadoras. Pero muchos profesionales de la comunicación no estarán de acuerdo con la afirmación de Hang en relación a las imágenes: "Es obscena la transparencia que no encubre nada, ni mantiene oculto, y lo entrega todo a la mirada. Hoy, todas las imágenes, mediáticas son más o menos pornográficas. (...) Son, a lo sumo, el objeto de un me gusta". Y sigue: "Las imágenes pornográficas, al estar desculturizadas, no dan nada que leer. Actúan sin mediación, como imágenes de propaganda, de forma táctil y contagiosa. (...) Se vacían para convertirse en espectáculo". Y termina golpeando fuerte: "La sociedad porno es una sociedad del espectáculo”.

¿Nos podemos considerar como la sociedad del espectáculo puesto que hemos convertido que lo transparente sea un ejercicio más de la exposición, más 
preocupada por mostrar la apariencia que el ser en sí mismo? "Exponer o exhibir no sirven de modo primario al logro del poder. Allí no se aspira al poder, sino a la atención. (...) Poder y atención no coinciden. Quien tiene poder tiene al otro, lo cual hace superflua la aspiración a la atención. Y esta última no genera automáticamente poder", dice Byung-Chul Han.

\section{Conclusión}

Hang consigue su objetivo. No escribe lo que el lector quiere leer, sino lo que realmente cree que debe escribir para alterar el concepto de transparencia que conocemos. Tener información de los demás, y por tanto el control sobre los demás, no nos garantiza la verdad, tampoco el poder. "La sociedad de la transparencia no sólo carece de verdad, sino también de apariencia. Ni la verdad ni la apariencia son tan aparentes. (...) Un argumento de información y comunicación no esclarece por sí solo el mundo". Y continúa Hang: "La transparencia y el poder se soportan mal. Al poder le gusta encubrirse en secretos. (...) Donde domina la transparencia no se da ningún espacio para la confianza”. ¿Hasta dónde los secretos en política pueden ser ocultos?

El autor altera los esquemas estratégicos de comunicación, desde la imagen hasta la concepción de la información para la transparencia. En el caso de las mujeres en política, aún resulta más grave. Puede que la solución, en esta sociedad de la desconfianza, no pase sólo por la transparencia, sino por estrategias de comunicación que proyecten valores y humanicen los rostros del poder enfocados hacia la construcción de confianza. La transparencia, en este libro, no resulta un fin en sí mismo. Tampoco el cómo se ha elevado exponencialmente a ésta hasta convertirla en una mera expositora de la apariencia -irreal- que todos quieren controlar.

Repensar la transparencia en comunicación y en comunicación política para diseñar estrategias enfocadas hacia la libertad sin control, hacia la confianza para la influencia y la movilización. Esa es la gran lección que se extrae de la obra, se esté de acuerdo o no con ella.

\section{Forma de citación}

MARTÍNEZ FERNÁNDEZ, Ángela Paloma: La sociedad de la transparencia. Revista Communication Papers, No8 (Monográfico II), páginas 60 a 63. Departamento de Filología y Comunicación de la Universidad de Girona. Recuperado el __ de de 2 de: http://www.communicationpapers.es 